\title{
The Impact of Instructors' Perceptions of E-Learning on the Quality of Online Teaching: A Case Study of the French Language Instructors at the University of Bahrain During COVID-19 Pandemic
}

\author{
Sara A. Bader ${ }^{1}$ \\ ${ }^{1}$ French Studies Center, University of Bahrain, Zallaq, Kingdom of Bahrain \\ Correspondence: Sara A. Bader, French Studies Center, University of Bahrain, Sakhir campus, Zallaq road, \\ Kingdom of Bahrain.
}

Received: August 15, 2021

doi:10.5539/ies.v14n12p152
Accepted: October 15, $2021 \quad$ Online Published: November 28, 2021

URL: https://doi.org/10.5539/ies.v14n12p152

\begin{abstract}
French language instructors at the University of Bahrain faced many challenges in adapting their teaching practices during the sudden transition to online teaching due to the COVID-19 pandemic. In this case study, we explore the French language instructors' perceptions of e-learning and their attitudes toward technology during the pandemic as well as their students' perceptions of the quality of their online teaching. The objective of this study is to analyze the relationship between instructors' perceptions and teaching performance. We conducted the study during the beginning of the sudden change to online teaching and administered online survey-based data collection instruments to gather information about French language instructors' perceptions and undergraduate students' satisfaction with the quality of French language online teaching. One year later, we completed data collection with semi-structured interviews of the instructors' perceptions and online teaching experience. The findings indicated that despite the abrupt switch to online teaching, instructors showed a prominent level of technology acceptance. However, the results indicated effective online teaching was highly correlated to instructors' pedagogical preparedness and self-efficacy level. Consequently, this study outlines key factors influencing the efficacy of e-learning, including pedagogical preparedness, instructors' self-efficacy, and information and communications technology literacy. In addition, in this study we propose implications for instructors' preparation and development.
\end{abstract}

Keywords: COVID-19, e-learning, French, language instructor, perception, quality

\section{Introduction and Literature Review}

In response to the vast spread of COVID-19, in March 2020, the University of Bahrain officially started a transition to e-learning to maintain social distance and continue teaching. French foreign language courses had never been delivered online, and such courses were not designed to be taught online. Therefore, instructors faced many challenges in adapting their teaching practices to the needs of online teaching. Some of the main challenges that the institution faced during the COVID-19 pandemic were training nonexpert instructors in a brief period to use e-learning platforms, ensuring their pedagogical preparedness to transform the curricula into an online resource (Dhawan, 2020), designing e-content and e-activities, adapting assessments to the new learning requirements (Rapanta et al., 2020), ensuring teaching presence (Rapanta et al., 2020), and creating an effective e-learning environment where students received support as in traditional face-to-face instruction through monitoring the learning process.

Many studies have been conducted to investigate higher education instructors' attitudes toward e-learning during the pandemic (Chang \& Fang, 2020), and researchers have sought to understand the challenges of online teaching. Some studies have concluded that successful practices used in traditional face-to-face instruction did not always translate into successful online teaching practices and that online teaching required adjustments to teachers' beliefs and pedagogical roles (Hsi Lin \& Zheng, 2015).

Perceptions of technology use vary from person to person, depending on instructors' beliefs (Kim, 2008). Chang and Fang (2020) explored online instructors' challenges during the COVID-19 pandemic; their findings indicated instructors were not well prepared for or accepting of online instruction. Some instructors possessed low skills in computer and internet-related tasks, and many preferred traditional course instruction methods (i.e., face to face) 
over online instruction (Rahayu \& Wirza, 2020). Rahayu and Wirza (2020) conducted a study to investigate teachers' perceptions of online English language learning during the pandemic. Their findings revealed that teachers showed a positive attitude toward the use of technology in online instruction during the pandemic; the teachers also felt they should develop their digital skills further, which proved the teachers had recognized the importance of technology in their instruction. Still, more than half the teachers did not agree on the effectiveness of online instruction because it lacks the qualities of in-person communication and interaction (Rahayu \& Wirza, 2020).

According to Rapanta et al. (2020), effective e-learning should not be considered new learning but efficient and enjoyable learning during the sudden transition. They proposed the essence of an online course is in the teaching presence, which they defined as the "learning design and organization, facilitating discourse and direct instruction" that enable students to reach certain learning outcomes. Their study focused on the pedagogical preparedness of university teachers with little to no experience in online teaching to provide expert insight into online learning regarding pedagogical content knowledge (Rapanta et al, 2020). In Saudi Arabia, Alshraideh (2021) investigated the perceptions of English as a foreign language (EFL) learners and teachers toward the use of online videos in EFL classes during the pandemic; the study's findings demonstrated that the teachers had a positive perception of the use of online videos, and they found videos a useful and effective method for teaching the English language. However, the content of online instructional videos must be carefully prepared and planned (Alshraideh, 2021).

Conversely, Maclntyre et al. (2020) examined the stress and coping responses of an international sample of language teachers; their study showed that during the pandemic, although teachers coped as well as they could, they felt significant stress. A study by Gao and Zhang (2020) confirmed this; they examined how English teachers at Chinese universities coped with the challenges of online teaching and how they perceived and responded to disrupted teaching when online teaching became the main mode of delivery. Their findings showed teachers faced psychological pressure during their preparation for online teaching because of a lack of proper information technology literacy for online teaching and because of invalid class management during online teaching (Gao \& Zhang, 2020). In addition, teachers were concerned about the efficacy of online teaching and worried about whether learning outcomes were being achieved - a common theme revealed in many studies (Rahayu \& Wirza, 2020).

Nonetheless, according to Garrett (2009) and Parmaxi (2020), the use of technology in language education has increased during the past decade. Many researchers have investigated the effectiveness of technology for language education and language skill development to explore whether technology and e-learning can support and facilitate language learning (Canal, 2020; Chi-Jen \& Gwo-Jen, 2018; Coverdale-Jones, 2000; Fung-Chuan \& Wen-Chi, 2015). Some researchers investigated foreign language instructors' perceptions and attitudes toward the use of technology for language learning (Alshraideh, 2021; Hsi Lin \& Zheng, 2015). Some scholars have stated that to better understand how technology affects language learning, it is important to consider the instructors' use of and expectations about technology (Davis et al., 1989; Gao \& Zhang, 2020; Kim, 2008) because successful integration of technology into teaching depends on the design of activities based on pedagogical priorities (Rovai et al., 2008). Canal and Al Rawashdeh (2018) noted effective online learning and teaching also depend on teachers' ability to effectively juggle pedagogical approaches, teacher and learner computer readiness, and course design. Rahayu and Wirza (2020) felt the key to effective online teaching lay in teachers' ability to innovate when designing and gathering learning materials and methods and when choosing the best applications in line with the materials and techniques. Thus, continuous professional development to ensure teachers' readiness will decidedly determine teachers' attitudes toward using technology for language instruction (Canal \& Al Rawashdeh, 2018). Liaw et al. (2007) believed the quality of e-learning is positively related to instructors' perceived enjoyment, usefulness, and self-efficacy in terms of e-learning; they noted these three factors are positively related to instructors' intent to use technology and e-learning. The theoretical framework of Liaw et al.'s study was based on the technology acceptance model (TAM) that Davis et al. (1989) developed. The TAM focuses on predicting and assessing users' initial preacceptance of technology through behavioral intention, attitude toward use, perceived usefulness, perceived ease of use, and external variables (Lee et al., 2003). According to the TAM, if the instructor perceives online teaching methods as easy to use, then they have a positive perception of e-learning (Rahayu \& Wirza, 2020). The TAM also guides the context of the current study to explore French language instructors' perceptions of online teaching.

Despite the varied number of significant challenges associated with teachers' attitudes toward the e-learning model, the impetus of this study is to contribute to a better understanding of how instructors' perceptions of e-learning influence the quality of their online instruction. According to Hsi Lin and Zheng (2015, p. 280), 
examining online pedagogy is essential to any assessment of the quality of online teaching, and evaluating teachers' perceptions toward online teaching - especially their transition from face-to-face to online teaching - could be beneficial to understanding their teaching practices. In this study, we investigate the relationship between instructors' attitudes toward e-learning and the quality of their teaching practice. According to Elango et al. (2008), student assessment of instructors' e-learning expertise is the best predictor of learning achievement and course satisfaction; they analyzed e-learners' perception of the quality of the e-learning process by asking them whether they were satisfied with the curriculum content, faculty support, delivery mode, and assessment. Elango et al. (2008) designed a questionnaire to analyze quality issues from e-learners' perspective. Based on this approach, in this study we explore and measure the quality of instructors' online teaching from students' perspectives to correlate the results with the instructors' perceptions and attitudes toward e-learning.

We aspire to answer two research questions with this study. First, what are the difficulties that affected instructors' technology acceptance during the precautionary period of COVID-19 (RQ1)? Second, to what extent did the instructors' perceptions of e-learning affect the quality of their online teaching (RQ2)?

\section{Methodology}

\subsection{Participants}

The case study took place at the French Studies Center of the University of Bahrain. The sample included four instructors: the total number of instructors who teach the French language at the University of Bahrain. The participants were between the ages of 38 and 57 years old.

The sample also included 172 undergraduate Bahraini students between 18 and 25 years old; $16 \%$ were male, and $84 \%$ were female. The participants were taking French language courses and fell into one of two categories: (a) students taking French as an elective subject and (b) students taking French as a minor subject. The French elective students were at a beginning level of French language proficiency, whereas the French minor students were at an intermediate or advanced level (A2-B1 levels, per the Common European Framework of Reference for Languages CECR).

\subsection{Instrument and Data Collection}

For this empirical case study, we used three online-based data collection instruments:

- A questionnaire on instructors' attitudes toward online teaching and the use of technology

- A survey on students' evaluations of the French courses

- Semi-structured interviews with instructors

\subsubsection{Instructors' Attitudes Toward the E-Learning Questionnaire}

The survey was based on the observations of several studies (Stepp-Greany, 2002; Yang \& Chen, 2007) that looked at the impact of instructors' attitudes on the effectiveness of e-learning (Liaw et al., 2007). The survey comprised two sections. The first section consisted of six questions about computer and internet experience, and the second section consisted of 19 questions about the instructors' attitudes toward e-learning. For the first section, the instructors had to evaluate their level of expertise in using technology as a teaching tool on a 3-point scale $(3=$ well-experienced, 2 = moderate experience, $1=$ no experience) well-experienced, moderate experience, no experience). In the second section, the instructors were asked to rate on a 3-point scale ( $3=$ agree, 2 = neither agree nor disagree, $1=$ disagree) statements about their attitude toward three dimensions of e-learning: enjoyment, usefulness, and behavioral intent to use e-learning as a teaching assistance tool. We administered the survey in June 2020 via a link shared with instructors through WhatsApp, and participants gave full consent before participating in the online survey.

\subsubsection{Students' Course Evaluation Survey}

Based on Elango et al.'s (2008) study on e-learners' perception of the quality of e-learning, we believe the student course evaluation survey that the university conducts is a suitable tool and provides full insight into instructors' online teaching performance. At the end of each semester, the University of Bahrain Department of Quality Assurance and Accreditation conducts the course survey via the student information system (SIS). The survey is sent to all students via an email containing an online link so that they can evaluate their courses and instructors. The survey measures students' perceived satisfaction of the five following dimensions of teaching practice:

- The design and planning of learning activities, for which students rate (a) the availability of the course syllabus online, (b) the content of the online course (e.g., videos, lecture notes, screencasts, podcasts), and (c) 
the comprehensiveness of the course (i.e., whether all learning outcomes were covered)

- The teaching process and learning support, for which students evaluate whether the online course content supported their learning

- Learners' assessments and feedback to measure (a) whether the online medium was used effectively to answer questions and provide them with feedback and (b) whether the online assessment was transparent and supported student learning

- The development of effective learning environments and approaches to student support and guidance, which aims specifically to examine students' satisfaction with online course delivery and determine whether it is interactive and engaging

- The overall course satisfaction, for which students express their feelings about whether online learning is an appropriate alternative to face-to-face learning under the current pandemic circumstances

The university sent the online survey to 585 undergraduate students of the French Studies Center, and 172 students participated. The survey contained seven statements related to the five aforementioned dimensions of teaching practice:

- The course syllabus was available online.

- The online course content (e.g., videos, lecture notes, screencasts, podcasts) was comprehensive (i.e., covered all the learning outcomes).

- The online course content supported my learning.

- The online medium was used effectively to answer my questions and provide me with feedback.

- The online assessment was transparent and supported my learning.

- The online course delivery was interactive and engaging.

- Online learning was an appropriate alternative to face-to-face learning under the current circumstances.

Students rated each statement for their French courses on a 5-point Likert scale ranging from 1 (strongly disagree) to 5 (strongly agree). The system generated descriptive statistics, and the average and the percentage were given for each item and category (Figure 1).

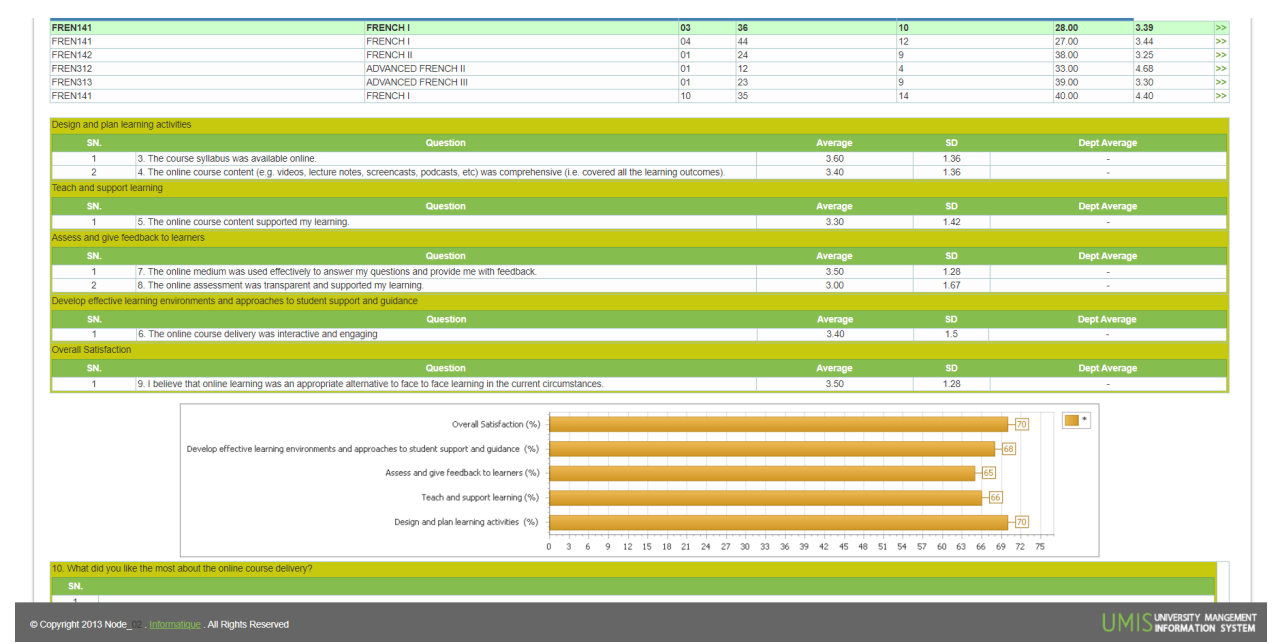

Figure 1. The course evaluation result format

Data were gathered from the system for the French courses the instructors had taught during the study period: March through June 2020. The data were presented anonymously, with the instructors' consent, to correlate the results of the instructors' perceptions survey.

\subsubsection{Instructors' Interviews}

We developed an online semi-structured interview protocol to examine (a) instructors' attitudes toward online teaching during the COVID-19 pandemic, (b) their experience with the shift from face-to-face to online learning, 
and (c) their challenges. We invited all four instructors to participate in individual 10- to 20-minute interviews in October 2021, and they all agreed to do so. There were nine related interview questions. We conducted the interviews online and recorded them using Microsoft Teams. Then, we prepared transcriptions for content analysis.

\subsubsection{Data Analysis}

We used both quantitative and qualitative research methods in this study. We analyzed the data collected from the survey about instructors' attitudes toward online teaching and technology usage using the Statistical Package for Social Sciences (SPSS Statistics, version 26). We adopted frequencies descriptive analysis to report all the categories as frequencies, percentages, and means. For the students' course evaluation survey, the SIS generated the results, then a report. For the qualitative data, we performed a content analysis of the interviews. Finally, we used the cumulative results to answer the research questions.

\section{Results and Discussion}

Items 1 through 6 of the survey about instructors' information communication technology (ICT) literacy revealed that instructors had a moderate level of perceived technological self-efficacy and that the massive integration of technology and the internet during COVID-19 was a new experience for them. Table 1 displays the results.

Table 1. Instructors' experience in using computers or internet technology for teaching

\begin{tabular}{|c|c|c|c|c|c|c|c|c|}
\hline & \multicolumn{8}{|c|}{$\mathrm{N}(\%)$} \\
\hline Items & Z & 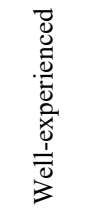 & $\begin{array}{l}\frac{0}{\pi} \\
\frac{\pi}{\delta} \\
\Sigma\end{array}$ & 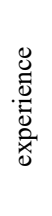 & 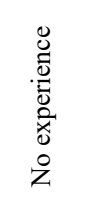 & $\begin{array}{l}\text { 寻 } \\
\text { 䒠 }\end{array}$ & 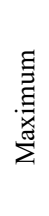 & 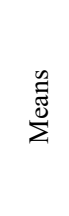 \\
\hline Q1. Experience using operating systems & 4 & $2(50)$ & $2(50$ & & 0 & 2 & 3 & 2.50 \\
\hline Q2. Experience using the internet & 4 & $3(75)$ & $1(25$ & & - & 2 & 3 & 2.75 \\
\hline Q3. Experience using word processing packages & 4 & $3(75)$ & - & & $1(25)$ & 1 & 3 & 2.50 \\
\hline Q4. Experience using PowerPoint & 4 & $3(75)$ & - & & $1(25)$ & 1 & 3 & 2.50 \\
\hline Q5. Experience using a computer as a teaching tool & 4 & - & $4(10$ & 00) & - & 2 & 2 & 2.00 \\
\hline Q6. Experience using e-learning & 4 & - & $4(10$ & 00) & - & 2 & 2 & 2.00 \\
\hline
\end{tabular}

The data collected from the interviews supported this finding. These data indicated some of the instructors did not use technology in their teaching practice, and most had never used a learning management system (LMS) before the sudden shift to online teaching during the pandemic.

R: Did you use technology in your teaching practice before the COVID-19 pandemic?

IN1: "No, I used technology for doing research and to self-inform, and I tried to implement some technology tools in the workshops, but not for teaching."

IN2: "No, I didn't. . . . Blackboard for me was something new at the beginning. I knew that it existed and that some staff was using it at the university for a long time, but I personally never tried to use Blackboard. The first time I used the Blackboard platform was during the COVID-19 pandemic."

One instructor noted having no experience using word processing packages or PowerPoint. According to Gao and Zhang (2020), a lack of proper ICT literacy for online teaching can make e-learning a complicated and challenging task. A statement by IN2 during the interview explained and supported that finding:

Q3: Did you face any difficulties in using technology in your teaching during the COVID-19 pandemic?

IN2: "Yes, when the students are online with me . . I could not, for example, insert or upload any other content or documents for my students. Even today, I cannot use PowerPoint and so on. Some students asked me to share a presentation or to send slides; I did not do it because I had difficulties. I do not know how to create a presentation using PowerPoint. ... I had difficulties using the features of the platform."

This statement shows the teacher's perceived technological self-efficacy and awareness of having a novice ICT literacy level in using basic technology tools such as PowerPoint. This reflects IN2's perceived ease of use, 
defined as the degree to which a person believes using a particular system would be free of effort (Rahayu \& Wirza, 2020, p. 399).

However, items 7 through 22 (Table 2) showed all instructors had highly positive attitudes toward e-learning. These included enjoyment, usefulness, and high behavioral intent to use e-learning as a teaching-assisted tool in the future.

Table 2. Survey of instructors' attitude toward the use of computers and e-learning

\begin{tabular}{lcccc}
\hline Set of items & N & Minimum & Maximum & Means \\
\hline Instructors' perceived enjoyment & 4 & 1 & 3 & 3 \\
Instructors' perceived usefulness & 4 & 1 & 3 & 3 \\
Instructors' behavioral intent to use e-learning & 4 & 1 & 3 & 3 \\
Instructors' perceived system satisfaction & 4 & 1 & 3 & 2.9 \\
Instructors' attitude toward the use of multimedia instruction & 4 & 1 & 3 & 2.75 \\
\hline
\end{tabular}

The data obtained from the instructors' interviews gave greater insight into their attitudes toward the use of technology and e-learning and their perceived enjoyment, usefulness, and high behavioral intent to use e-learning as a teaching-assisted tool in the future. First, the data revealed IN2 did not enjoy using e-learning, as expressed in the following statement:

IN2: "In the beginning, it was a struggle. It was hard, to be honest. As you know, we attended training workshops that helped us, but for me, at the beginning it was hard. Especially [during] the first semester and even the second semester of the pandemic period, I had difficulties. Yes, we were delivering the lectures, but it was hard. . . Therefore, there were difficulties, and it was a struggle at the beginning. Even the students struggled in general . . because. . . Blackboard for me was something new at the beginning."

The reason for IN2's lack of perceived enjoyment was not because of Blackboard; all the instructors stated that online teaching and the use of the platform were new to them, and they still found online teaching useful and enjoyable. A low level of technological self-efficacy and ICT literacy in general caused IN2's lack of enjoyment.

Second, we found different perceptions from instructors concerning perceived e-learning usefulness. Perceived usefulness is defined as "the degree to which a person believes using a particular system will enhance their job performance" (Rahayu \& Wirza, 2020, p. 396). IN1 measured the usefulness of e-learning via her students' results and performance. Although both IN2 and IN3 agreed that technology would be more useful if it were implemented in a blended approach of teaching and learning, they believed physical presence and face-to-face interaction in foreign language teaching are essential. This agrees with the findings of Rahayu and Wirza (2020), whose participants found online learning was impractical because it lacked the qualities of communication and interaction. Moreover, IN4 found the usefulness of e-learning lay in the instructor's ability to use it.

The instructors' statements about their perceived e-learning and technology usefulness were as follows:

IN1: "With the experience that I went through, I think that it is useful, as the results of the students' performance indicate. . . For me, I found it interesting and extremely useful. I came along smoothly with the use of technology in teaching."

IN2: "It is useful in a pandemic situation. . . . I think it is useful for teaching French as a foreign language. However, I think that if we could blend face-to-face with e-learning . . . that it would be more useful."

IN3: "It is useful. If we overcome the pandemic, I prefer that we go back to face-to-face teaching because it is a foreign language. We could use the labs and the workshops, but we should continue using the platform as a supporting learning tool. I think that will be very useful."

IN4: "E-learning is very useful for teaching and learning the French language. As a teacher, I was able to expose my students to many educational resources, and it facilitated many tasks for me, such as creating and receiving assignments, giving feedback, creating e-rubrics for the exams, and sharing videos and audio [files]. E-learning is useful when the teacher knows how to use it in their class for their teaching purpose. E-learning could also be useful for the students; they have access to the information from wherever they are and whenever they wish." 
The survey data also showed all instructors highly perceived technology acceptance and intent to improve. This finding is expressed prominently in IN2's statement:

"I had difficulties using the features of the platform. The platform contains many features, but I need to attend a lot of training workshops. . . The more I learn from the training workshops, the more I feel that I need to attend more training workshops. . . I do not think that there will be any issues. I find that we managed to go on, and we learned many things. Still, I would like to learn more; therefore, if there is any workshop, I [will] attend to learn more, even if it is the same workshop. After having to use e-learning, I feel that I am more able to go on and teach, and I have improved and developed some skills."

This supports the findings of Rahayu and Wirza (2020), who found the conditions of online teaching force teachers to learn ICT. It also supports the findings of Hoq (2020), who claimed teachers welcomed the idea of modern technology in their teaching practice despite their moderate level of self-efficacy; this reflects their intent to improve and continue to integrate technology in their teaching. IN2's statement suggests that improvements in ease of use influenced his intent to improve and to use e-learning, which led to a positive perception and attitude (Rahayu \& Wirza, 2020). Additionally, regarding the quality of the e-learning environment, the survey revealed instructors IN1, IN3, and IN4 believed system satisfaction and multimedia instruction are key factors, whereas instructor IN2 displayed a neutral attitude toward using Microsoft Word and PowerPoint files as tools for multimedia instruction. Consequently, the instructors' self-efficacy and ICT literacy influenced their attitudes toward using technology and multimedia instruction. Confidence and technology competency led to a positive attitude toward using e-learning tools for multimedia instruction.

These findings led us to explore how the design of pedagogical resources and the quality of online teaching were affected by the instructors' perceptions of e-learning, their perceived technological self-efficacy, and their level of ICT literacy during the COVID-19 pandemic.

Correlating the data obtained from the students' e-course evaluation surveys with the data from the instructors' perceptions survey, we found the following results. IN1, who reported moderate experience in using ICT and e-learning as teaching tools, received an average rating of 3.37 out of 5 for the quality of online courses. IN2, who reported having no experience using ICT or e-learning as teaching tools and expressed a neutral attitude toward using multimedia instruction and e-learning tools, received the lowest overall average of 3.33 out of 5 for the quality of his online courses. IN3 and IN4, who reported having valuable experience using ICT and e-learning as teaching tools, received averages of 3.74 and 4.12 out of 5 , respectively, for the quality of their online courses. Figure 2 shows the student satisfaction results attributed to each instructor.

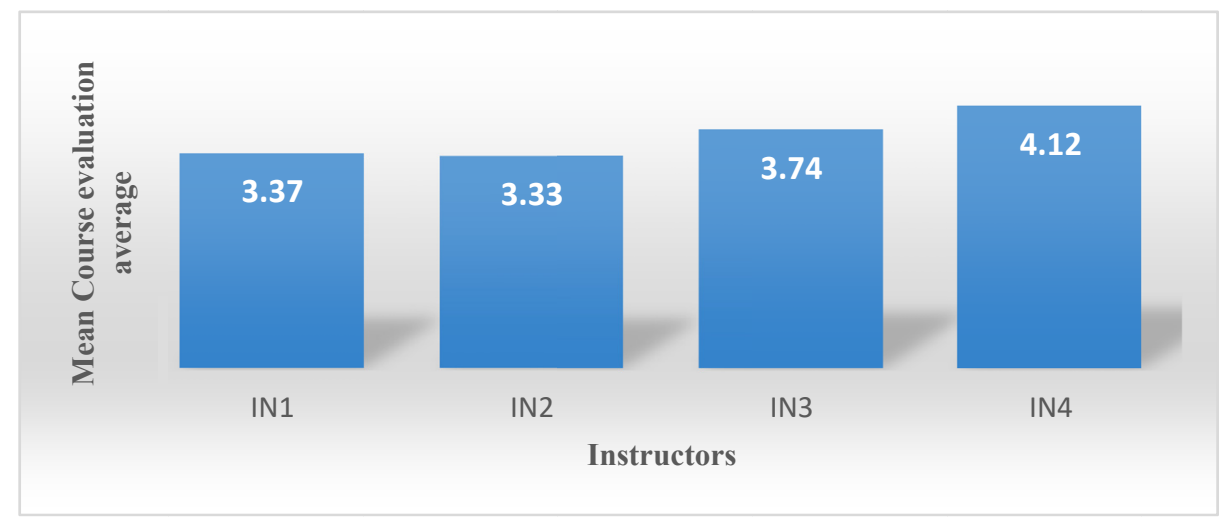

Figure 2. Overall average of students' evaluation results of French courses per semester

To justify IN4's high overall survey results, we examined his additional skills. He was the only instructor who reported having used the LMS (Blackboard) before the pandemic.

Q1: "Did you use technology in your teaching practice before the COVID-19 pandemic?"

"Yes, I used technology in my teaching practice. I am a fan of using the digital textbook in my classroom rather than the classic paper textbooks. . . I created PowerPoint presentations to share with my students during class; I used YouTube videos. I used the whiteboard and the language lab, 
and I used the Blackboard platform to upload some of my classes' materials so that students could have them and go over them as much as they wanted."

Correlated with the data from the interview, the overall course satisfaction results for IN2 revealed he was aware of the negative impact that his lack of technological self-efficacy and his low level of ICT literacy had on the quality of his teaching.

\section{Q7: Did you find that this challenge and these difficulties affected the quality of your teaching practice? \\ IN2: "Yes, they did. They affected the results of my course's student evaluation. Especially in the first semester of the shift to e-learning, the results of my students' course evaluations dropped. Why did they drop? Because there were things that I was not able to do or I did not know how to use. So, as a beginning, the takeoff was hard. I only had one workshop, and the next day we had to start the online teaching and to prepare for exams. I felt it difficult. . . It did affect the quality of my teaching. . . So, Ifeel that online teaching affected me a lot as a teacher."}

The course evaluation results for each teaching area showed the aspects of teaching were affected by instructors' barriers, as defined by Mailizar et al. (2020). For example, Figure 3 demonstrates the results of the student course evaluation for three of the instructors (IN1, IN2, and IN3) who were teaching the same French elective course. The figure shows that instructor IN2, who reported a low level of technological self-efficacy, received the lowest average for the design and planning of learning activities, which are described under the notion of teaching presence (Rapanta et al., 2020). Therefore, this result reflects the instructor's lack of pedagogical preparedness and pedagogical content knowledge for online teaching. The results also show IN2 received a low score in the teaching and support category, which Rapanta et al. (2020) believed to be the essence of effective online teaching. Moreover, IN2 received a low score in "assessing and giving feedback to learners," which could indicate, according to Rapanta et al. (2020), that IN2 was unable to adapt the assessment to the e-learning requirements. This led to an overall student course satisfaction average of $61 \%$.

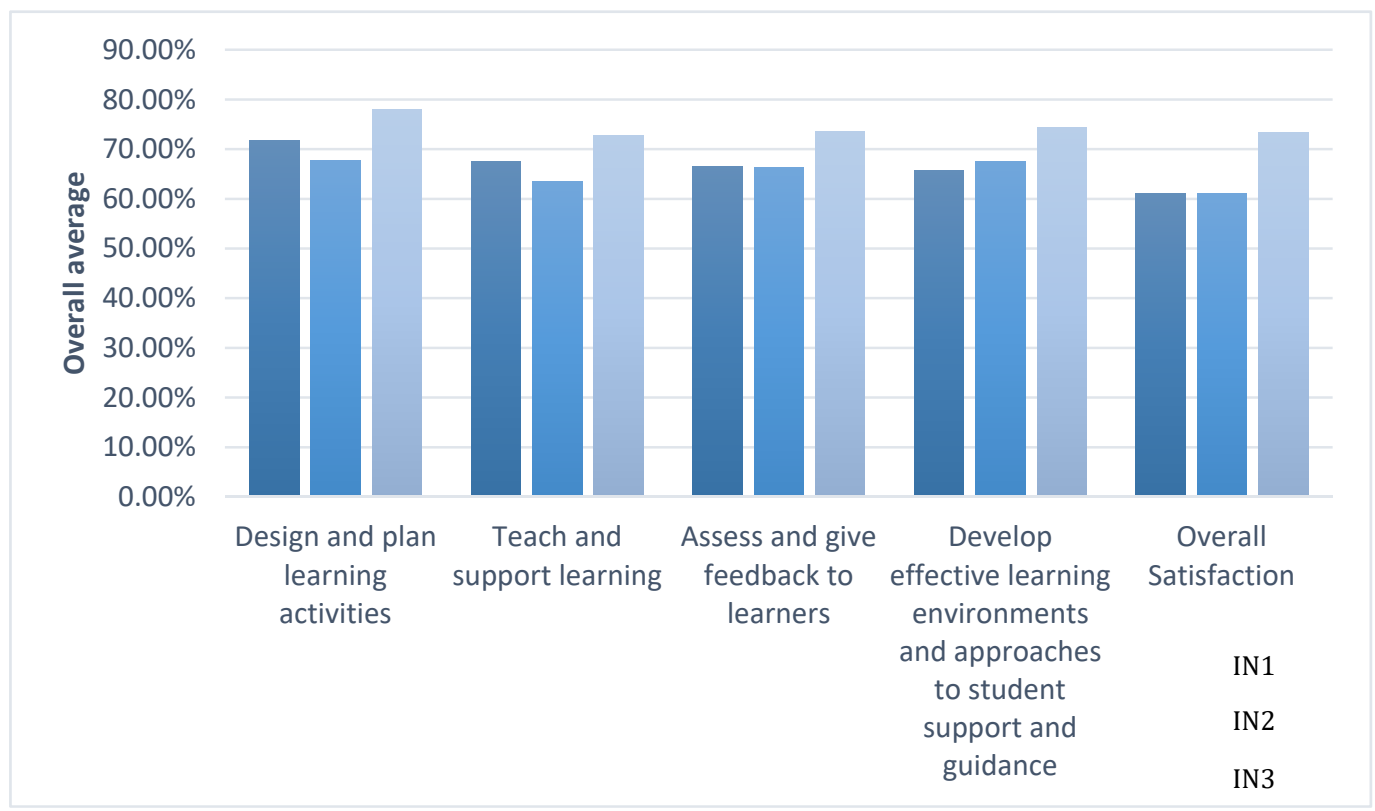

Figure 3. Students' evaluation results for the French elective courses and instructor

This result supports Chang and Fang's (2020) findings concerning unskilled teachers' use of platforms and tools, and it complements the results found in both the instructors' perceptions from the e-learning survey and the data from the instructors' interviews. In addition, this finding reveals IN2's perceptions of e-learning and perceived technological self-efficacy influenced the quality of his online teaching, which was reflected in the students' overall satisfaction of his online courses. By contrast, IN3, who reported a high level of self-efficacy, received the highest mean result in all online teaching activity areas, leading to an overall average of $74 \%$.

Figure 4 shows the results of the student course evaluations for IN2, IN3, and IN4, who were teaching French 
minor courses. The results show students were highly satisfied with IN4's online teaching, especially in the categories of "design and plan learning activities" and "develop effective learning environments and approaches to student support and guidance." This result supports Hoq's (2020) claim that digitally confident instructors are vital to success in e-learning.

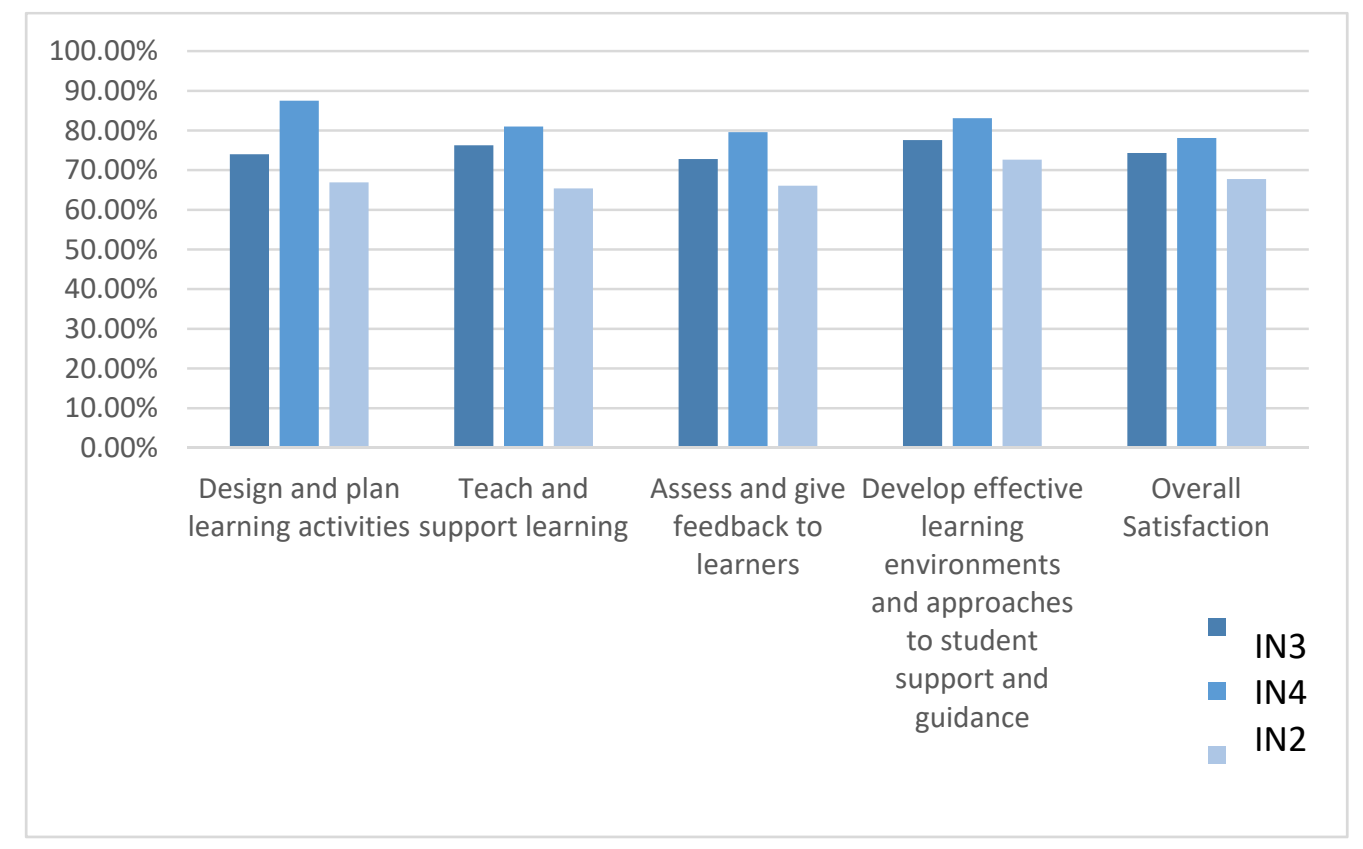

Figure 4. Student evaluation results for the French minor courses and instructors

The findings confirm the instructors' pedagogical content knowledge preparedness for e-learning during the pandemic depended on (a) their prior experience with using technology and the LMS in their teaching practice, (b) their perceptions of e-learning and technology, and (c) their technological self-efficacy. These were key factors for predicting the quality of online teaching through the students' overall satisfaction with the online courses, and these results align with those of previous research (Chang \& Fang, 2020; Rapanta et al., 2020).

\section{Conclusion and Implications}

E-learning has seen its greatest use to date during the COVID-19 pandemic, which made it the only effective teaching method to ensure the continuous delivery of instruction. Because of the sudden shift to e-learning, many challenges emerged for both students and instructors in higher education institutions worldwide. With this study, we provide insight into the challenges that French instructors at the University of Bahrain faced during the pandemic.

Answer to RQ1: What are the difficulties that affected instructors' technology acceptance during the COVID-19 pandemic?

The study revealed that self-efficacy in the LMS (Blackboard) was the main challenge that instructors had to overcome. Instructors who had used Blackboard as a teaching tool before the pandemic were less affected in their online teaching practice by the abrupt shift to e-learning. The study also revealed that technological self-efficacy and ICT literacy were key factors that had a significant impact on online teaching practices and their quality. The more instructors perceived a high level of technological self-efficacy, the better students rated their teaching.

The instructors highlighted other challenges, such as students' behavior and self-discipline, that made it difficult for them to ensure effective instructor-student interaction. The study also demonstrated that despite the challenges, instructors had a positive attitude toward e-learning as well as a high level of technology acceptance and desire to improve and to continue using technology as a teaching tool post-COVID-19.

Answer to RQ2: To what extent did the instructors' perceptions of e-learning affect the quality of their online teaching? 
This study demonstrated that instructors' perceived ease of use and enjoyment of technology affected the four dimensions of teaching practice, including students' overall satisfaction with the quality of online teaching.

Thus, this study suggests that at the institutional level, further training should be given to instructors to ensure e-learning effectiveness and to enhance teaching presence, digital literacy, and the quality of online teaching.

\section{Limitations and Recommendations}

Although most researchers conducting studies of similar interest have oriented their investigation to the effects of emergency remote teaching and COVID-19 on higher education, in the current study, we provide new evidence on the impact of foreign language instructors' perceptions of e-learning on the quality of the online learning experience. The significance of the current study is that it correlates instructors' perceptions with their online teaching performance from both instructor and student perspectives. Our aim was to gain global insight into the effectiveness of e-learning during COVID-19, whereas most prior studies have focused on a single aspect. Despite its significance, the current study has limitations. First, all study participants were French instructors at the French Studies Center at the University of Bahrain. Other foreign language contexts may exhibit different results and variables from those in this study. Therefore, researchers conducting future studies should consider e-learning in the context of other foreign languages to gain greater insight into online foreign language teaching during COVID-19. Moreover, we believe that despite the instructors' positive attitudes toward online teaching and their motivation to integrate technology into their teaching practices, researchers should further investigate the pedagogy for online teaching and the barriers to employing technology in teaching to determine instructors' needs and uncover solutions to enhance their digital skill sets.

\section{References}

Alshraideh, D. S. (2021, March). EFL learners and teachers' perception towards the use of online videos in EFL classes. Arab World English Journal, 12(1), 215-228. https://doi.org/10.24093/awej/vol12no1.15

Canal, L. (2020). The effect of virtual exchange on oral skills and motivation. Language Learning \& Technology, 24(3), 103-119.

Canal, L., \& Al Rawashdeh, A. (2018, October). Teacher training and teachers' attitudes towards educational technology in the deployment of online English language courses in Jordan. Computer Assisted Language Learning, 32(7), 639-664. https://doi.org/10.1080/09588221.2018.1531033

Chang, C. L., \& Fang, M. (2020). E-learning and online instructions of higher education during the 2019 novel coronavirus diseases (COVID-19). Journal of Physics: Conf. Ser. 1574 012166, 1-5. https://doi.org/10.1088/1742-6596/1574/1/012166

Chi-Jen, L., \& Gwo-Jen, H. (2018, April). A learning analytics approach to investigating factors affecting EFL students' oral performance in a flipped classroom. Journal of Educational Technology \& Society, 21(2), 205-219.

Coverdale-Jones, T. (2000). The use of video-conferencing as a communication tool for language learning: Issues and considerations. CALL Journal, 32(1), 27-40. https://doi.org/10.17161/iallt.v32i1.8308

Davis, F., Bagozzi, R., \& Warshaw, P. (1989). User acceptance of computer technology: A comparison of two theoretical models. Management Science, 35(8), 982-1003. https://doi.org/10.1287/mnsc.35.8.982

Dhawan, S. (2020). Online learning: A panacea in the time of COVID-19 crisis. Journal of Educational Technology Systems, 49(1), 5-22. https://doi.org/10.1177/0047239520934018

Elango, R., Gudep, V., \& Selvam, M. (2008). Quality of e-learning: An analysis based on e-learners' perceptions of e-learning. The Electronic Journal of e-Learning, 6(1), 31-44.

Fung-Chuan, O., \& Wen-Chi, V. (2015). Using mixed-modality learning for second language vocabulary acquisition. Journal of Educational Technology \& Society, 18(3), 309-322.

Gao, L. X., \& Zhang, L. J. (2020, September). Teacher learning in difficult times: Examining foreign language teachers' cognitions about online teaching to tide over COVID-19. Frontiers in Psychology, 11, 1-15. https://doi.org/10.3389/fpsyg.2020.549653

Garrett, N. (2009). Computer-assisted language learning trends and issues revisited: Integrating innovation. The Modern Language Journal, 93, 719-740. https://doi.org/10.1111/j.1540-4781.2009.00969.x

Hoq, M. Z. (2020). E-learning during the period of pandemic (COVID-19) in the kingdom of Saudi Arabia: An empirical study. American Journal of Educational Research, 8(7), 457-464. 
Hsi Lin, C., \& Zheng, B. (2015). Teaching practices and teacher perceptions in online world language courses. Journal of Online Learning Research, 1(3), 275-304.

Kim, H. (2008). Beyond motivation: ESL/EFL teachers' perceptions of the role of computers. CALICO Journal, 25(2), 241-259.

Lee, Y., Kozar, K., \& Larsen, K. (2003). The technology acceptance model: Past, present, and future. Communications of the Association for Information Systems, $12(1), 50$. https://doi.org/10.17705/1CAIS.01250

Liaw, S. S., Huang, H. M., \& Chen, G. D. (2007). Surveying instructor and learner attitudes toward e-learning. Computers \& Education, 49(4), 1066-1080. https://doi.org/10.1016/j.compedu.2006.01.001

MacIntyre, P. D., Gregersen, T., \& Mercer, S. (2020). Language teachers' coping strategies during the Covid-19 conversion to online teaching: Correlations with stress, wellbeing and negative emotions. System, 94, 102352. https://doi.org/10.1016/j.system.2020.102352

Mailizar, M., Almanthari, A., Maulina, S., \& Bruce, S. (2020). Secondary school mathematics teachers' views on e-learning implementation barriers during the COVID-19 pandemic: The case of Indonesia. EURASIA Journal of Mathematics, Science and Technology Education, 16(7), 1-9. https://doi.org/10.29333/ejmste/8240

Parmaxi, A. (2020, May). Virtual reality in language learning: A systematic review and implications for research and practice. Interactive Learning Environments, 29(6), 1-14. https://doi.org/10.1080/10494820.2020.1765392

Rahayu, R. P., \& Wirza, Y. (2020, December). Teachers' perception of online learning during pandemic COVID-19. Jurnal Penelitian Pendidikan, 20(3), 392-406. https://doi.org/10.17509/jpp.v20i3.29226

Rapanta, C., Botturi, L., Goodyear, P., \& Guardia, L. (2020). Online University Teaching During and After the Covid-19 crisis: Refocusing Teacher Presence and Learning activity. Postdigital Science and Education, 2(1), 923-945. https://doi.org/10.1007/s42438-020-00155-y

Rovai, A., Wighting, M., Baker, J., \& Grooms, L. (2008). Development of an instrument to measure perceived cognitive, affective, and psychomotor learning in traditional and virtual classroom higher education settings. Internet and Higher Education, 12(1), 7-13. https://doi.org/10.1016/j.iheduc.2008.10.002

Stepp-Greany, J. (2002). Student perception on language learning in a technological environment: Implications for the new millennium. Language Learning \& Technology, 6(1), 165-180.

Yang, S., \& Chen, Y. J. (2007). Technology-enhanced learning: A case study. Computers in Human Behavior, 23(1), 860-879. https://doi.org/10.1016/j.chb.2006.02.015

\section{Copyrights}

Copyright for this article is retained by the author(s), with first publication rights granted to the journal.

This is an open-access article distributed under the terms and conditions of the Creative Commons Attribution license (http://creativecommons.org/licenses/by/4.0/). 